\title{
Empirical fragility curves for Peruvian school buildings
}

\author{
A. Muñoz, M. Blondet, R. Aguilar \& M.-A. Astorga \\ Department of Civil Engineering, Catholic University of Peru, Peru
}

\begin{abstract}
This paper describes an estimation of economic losses in Peruvian educational buildings for different levels of seismic action. Opinions of experts were processed to generate seismic intensity versus damage relationships. Economic losses were then expressed through fragility curves and damage matrices. For frequent earthquakes (50-year return period) a $50 \%$ loss would be expected in adobe buildings and 20\% loss in confined masonry structures built before 1997 . During severe earthquakes (500-year return period) only confined masonry structures built after 1997 would be repairable at a cost of around $40 \%$ of their original cost.

Keywords: fragility curves, damage matrices, 1997 Peruvian seismic code, seismic lose, types of Peruvian school buildings.
\end{abstract}

\section{Introduction}

After earthquakes, Peruvian authorities allocate large quantities of resources to recover the educational infrastructure affected. The recovery usually consists in repairing the least affected buildings or retrofits and reinforcing the worst affected ones.

Experience has shown that damage to buildings could be significantly reduced by strengthening work done before earthquakes. It is not possible for the Peruvian government to handle a national strengthening program, so it is necessary to develop a plan to reduce the infrastructures' seismic risk gradually.

As a contribution to this national plan, we have identified the most representative buildings and we have made an estimation of the seismic behaviour using tools to quantify losses. 


\section{Educational buildings in Peru}

In Peru there are approximately 41000 public schools constructed at different periods of time, with different architecture and materials. There are buildings of reinforced concrete, masonry, wood, "adobe", "sillar" and even mixed constructions such as clay-sillar masonry or quincha-adobe constructions.

According to the Ministry of Education's report [1], the materials most typically used for school buildings are adobe, concrete-masonry and wood.

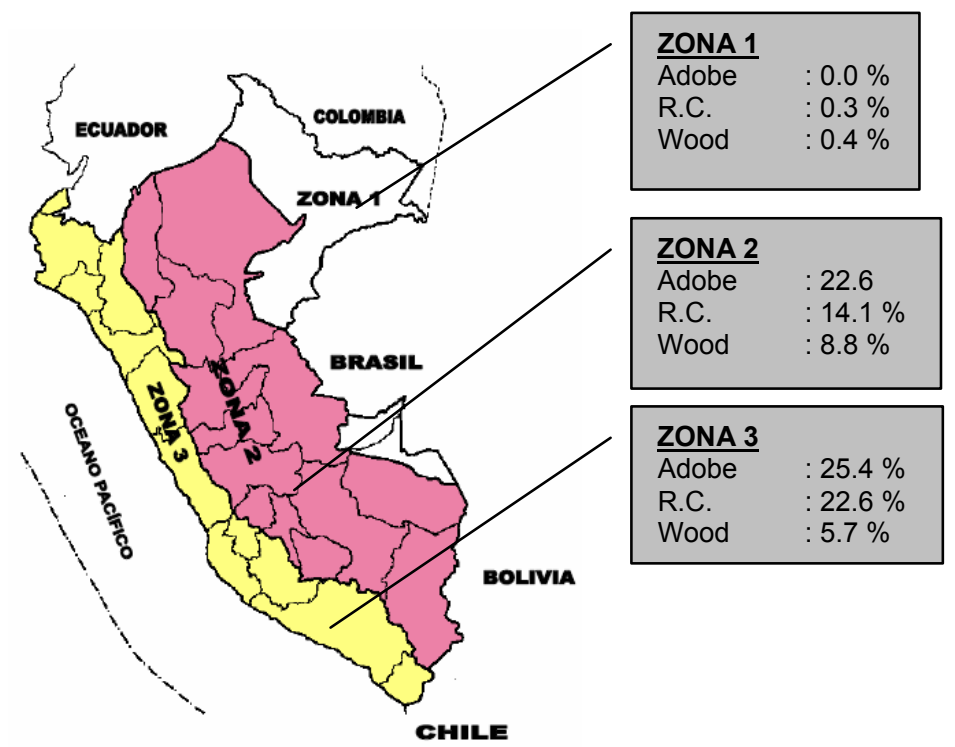

Figure 1: Peruvian school distribution according to the prevailing construction material.

Figure 1 shows the school distribution according to the prevailing material in the three seismic zones established by the Peruvian seismic design code [2].

Adobe buildings represent $48 \%$ of the total buildings and these are located in the highest Peruvian seismic zones. Reinforced concrete or masonry buildings represent $37 \%$, and almost all of them are located in the highest seismic zones.

With the help of the "National Institute for Education and Health Infrastructure - INFES" (in charge of Peruvian school buildings between 1993 and 2003) we have identified five types of buildings as the most representative in the country.

\subsection{Modern building}

This type has been built since 1997 following the Peruvian seismic code, which in that year significantly raised the rigidity and lateral resistance requirements. The typical building has a rectangular plan, with one, two or three stories and 
$7.80 \mathrm{~m} \times 7.80 \mathrm{~m}$ square classrooms. In the longitudinal direction, the building has two frames with big columns; and in the transverse direction, confined masonry walls. The roofs are lightened unidirectional slabs $0.20 \mathrm{~m}$ thick.

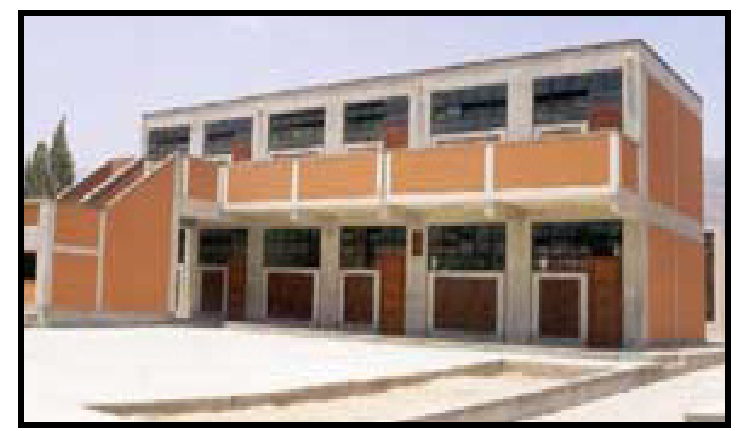

Figure 2: 780 Modern buildings.

\subsection{Pre SDC-1997 building}

This type had been built prior to 1997 (Figure 3). Its architecture is similar to the 780 modern building. In the longitudinal direction the building has two frames with weak columns and in the transverse direction confined masonry walls. The roofs are lightened unidirectional slabs $0.20 \mathrm{~m}$ thick. This type of building has suffered significant damage in past earthquakes. The problems were mainly due to the limited lateral rigidity that triggers the "short column" problem.

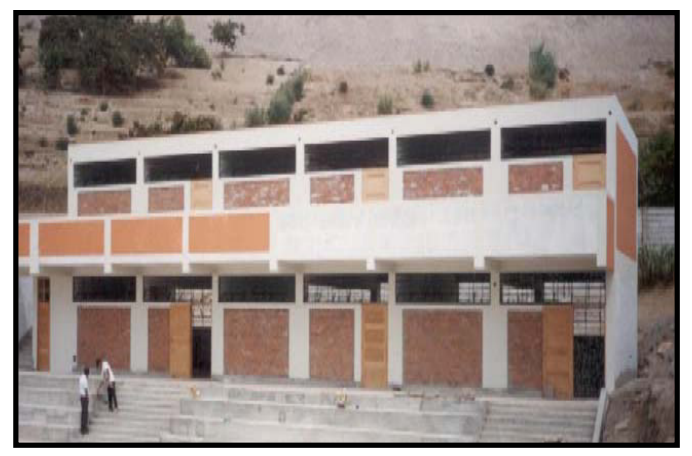

Figure 3: 780 pre Seismic Design 1997 Code buildings.

\subsection{Big school building}

These buildings were built 50 years ago (Figure 4). They have two or three stories with approximately $10 \mathrm{~m}$-long classrooms. Its plan area is more than double that of the 780 buildings. In the longitudinal direction the building has 
three edges of columns and in the transverse direction confined masonry walls. The roofs are lightened unidirectional slabs $0.20 \mathrm{~m}$ thick.

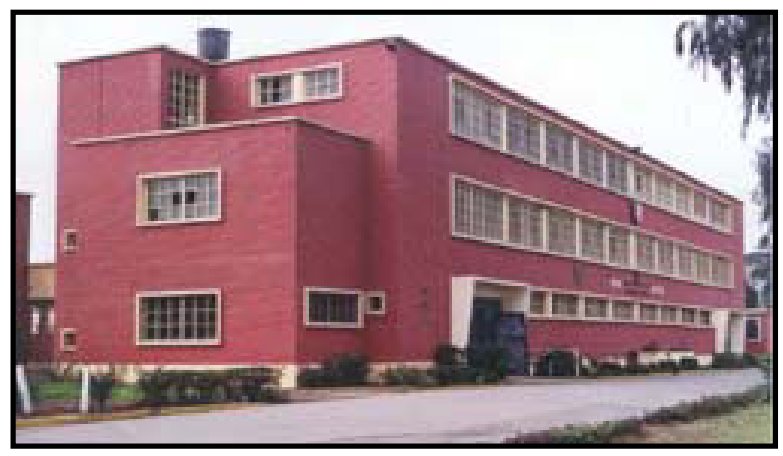

Figure 4: Big school buildings.

\subsection{Adobe building}

These buildings vary greatly in dimensions and quality of materials. The Government does not have a typical module. For our purposes, we have considered as the typical building a single story rectangular plan with two or three classrooms (Figure 5). The walls are orthogonal to each other and are $0.40 \mathrm{~m}$ thick. The roof is light and tilted.

Adobe buildings

\subsection{High Educational Pre 1997-SDC building}

These are two- to five-story buildings (Figure 6) with rectangular plan similar to the big school buildings. The structural system consists of three reinforced concrete frames in the longitudinal direction and confined masonry walls in the transverse direction. The roofs are lightened unidirectional slabs $0.20 \mathrm{~m}$ thick.

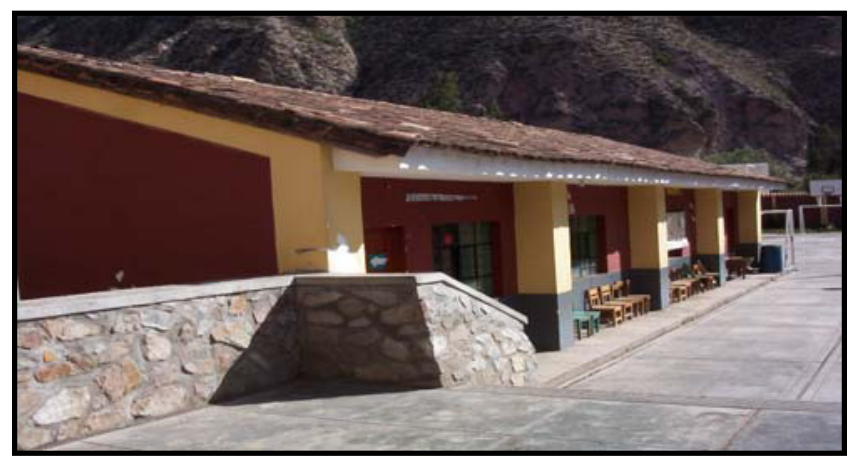

Figure 5: Adobe buildings. 


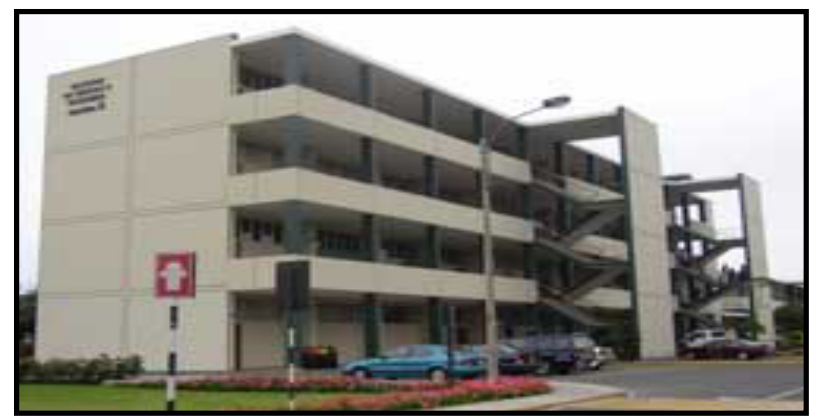

Figure 6: High educational pre 1997- SDC buildings.

\section{Seismic loss estimation}

The seismic intensity has been expressed using the Mercalli Modified (MM) scale and also using the peak ground acceleration. The relation between these two indicators is presented in Table 1.

Table 1: $\quad$ Relation between seismic intensity and PGA.

\begin{tabular}{|c|c|l|}
\hline IMM & PGA & \multicolumn{1}{c|}{ Description } \\
\hline V & $<0.05$ & Felt by some people. \\
\hline VI & $0.05-0.10$ & Felt by everybody. \\
\hline VII & $0.10-0.20$ & Negligible damage in well design-built buildings. \\
\hline VIII & $0.20-0.35$ & Slight damage in well design-built buildings. \\
\hline IX & $0.35-0.50$ & Serious damage in special designed structures. \\
\hline X & \multirow{2}{*}{$>0.50$} & Building's destruction. \\
\cline { 1 - 1 } XI & Few buildings remain standing. \\
XII & & Total destruction and changes in the landscape. \\
\hline
\end{tabular}

In order to quantify earthquake damage we use the ratio between the loss value and the replacement value. This ratio, eqn. (1), is called Damage Factor (DF).

$$
\text { Damage Factor }(\mathrm{DF})=\frac{\text { Lost Value }(\mathrm{LV})}{\text { Replace Value }(\mathrm{RV})}
$$

Limits have been established for the DF in ATC13 [3] and seven damage levels (DL) have been defined as shown in Table 2. 
Table 2: $\quad$ Damage levels.

\begin{tabular}{|l|c|l|}
\hline \multicolumn{1}{|c|}{ DL } & DF limits & \multicolumn{1}{|c|}{ Description } \\
\hline 1. None & 0 & No damage \\
\hline 2. Very light & $0-0.01$ & $\begin{array}{l}\text { Light, limited and located damage, repairs not } \\
\text { required. }\end{array}$ \\
\hline 3. Light & $0.01-0.1$ & $\begin{array}{l}\text { Significant and located damage (few elements) } \\
\text { repairs not required. }\end{array}$ \\
\hline 4. Moderate & $0.1-0.3$ & Significant located damage, repairs required. \\
\hline 5. High & $0.3-0.6$ & Extensive damage, major repairs required. \\
\hline 6. Severe & $0.6-0.99$ & $\begin{array}{l}\text { Extensive major damage, demolishing and repairs } \\
\text { required. }\end{array}$ \\
\hline 7. Collapse & 1 & Total destruction. \\
\hline
\end{tabular}

The intensity-damage relation was handled using probability density functions. Using these relations, fragility curves and damage matrixes have been obtained in order to quantify losses.

There is no statistical information available about the seismic behavior of Peruvian school buildings, so we gathered expert opinions to obtain basic information to create probability functions.

\section{Delphi method}

We collected and handled the experts' opinions using the Delphi method [4]. We described the structural characteristics of school buildings and designed a form to obtain the damage estimation under several seismic severity levels. For each level we asked for the DL and the possible values for mean, maximum and minimum damage factor (MDF, Vmin, and Vmax respectively - Figure 7).

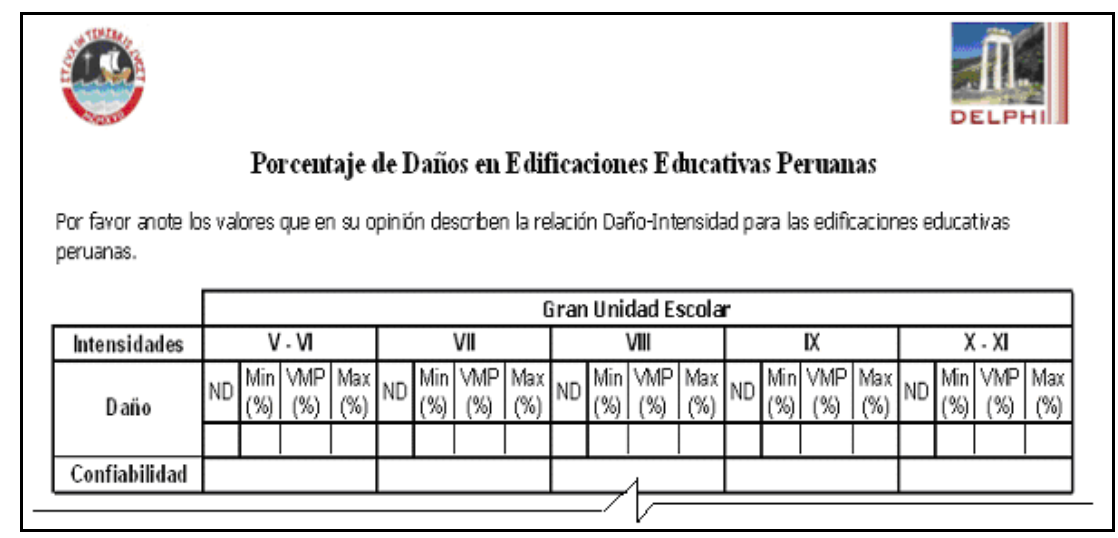

Figure 7: $\quad$ Form to collect experts' opinions. 
We communicated with the group of experts by internet and also by printed and digital means. The internet direct link to access the web page is http://www.pucp.edu.pe/secc/civil/dsrep/. This web page contains information about the Delphi method, principal characteristics of school buildings, a small image gallery and the results of the work.

\section{Density functions, fragility curves and damage matrices}

Damage distribution was modeled using the Beta Function because of its simplicity and adaptability to the information of the group of experts (Figure 8). We assumed that the estimation of the mean damage factor (MDF) corresponds to the mean value of the Beta Distribution and that $90 \%$ of the occurrence's probability is between the extreme values Vmax and Vmin [3].

With the mean values obtained from the group of experts, damage probability distribution functions $(p)$ were created for each intensity and for each type of Peruvian school building.

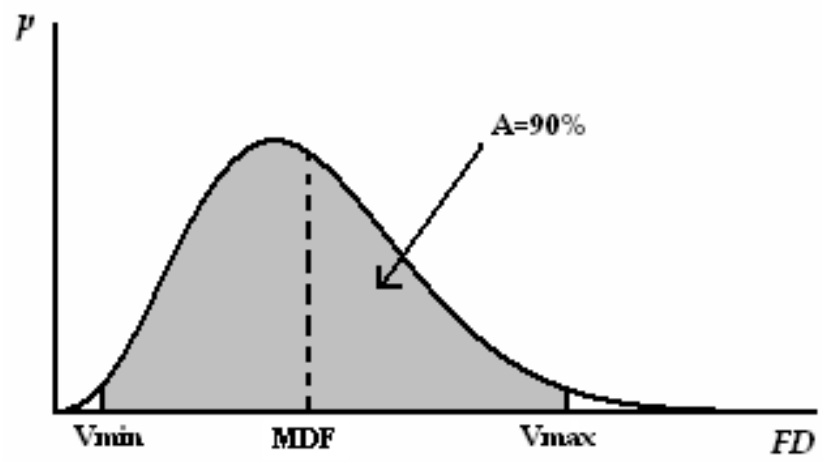

Figure 8: Beta function assumed to represent the damage distribution.

Fragility curves were determined computing the exceeding probabilities (E.P) corresponding to the extreme value of each damage limit in each seismic intensity, eqn. (2). For the damage matrices it was necessary to determine the occurrence's probability $(q)$ of each damage state in each intensity, eqn. (3).

$$
\begin{gathered}
E . P=1-P=1-\int_{0}^{d_{i}} p d D F \\
q=\int_{d \min }^{d \max } p d D F
\end{gathered}
$$


As a result of this procedure, we obtained fragility curves and damage matrices corresponding to the five types of Peruvian school buildings. Figure 9 and Table 3 show the results for the 780 modern building.

Using these tools, losses could be represented as the product of the mean damage factor and the construction value. Figure 11 corresponds to 50 "780 Pre 1997-SDC" buildings whose construction value was US\$ 4800 000. In this type of buildings, for intensities greater than VIII+, the damage factor exceeds $60 \%$. From this limit on, we must consider total loss [5] and the cost of the loss will be the same as the initial construction value.

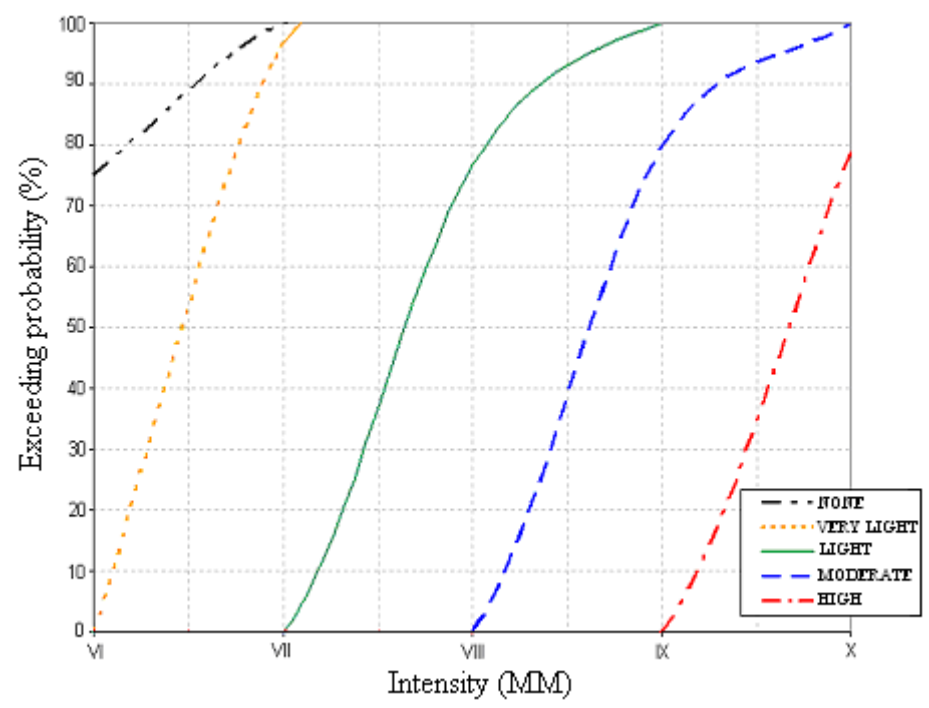

Figure 9: $\quad$ Fragility curves for 780 modern building.

Table 3: $\quad$ Damage matrix for 780 modern building.

\begin{tabular}{|l|c|c|c|c|c|c|}
\hline \multirow{2}{*}{$\begin{array}{c}\text { Damage } \\
\text { Level }\end{array}$} & $\begin{array}{c}\text { Central } \\
\text { damage factor }\end{array}$ & \multicolumn{5}{|c|}{ Damage probability (\%) } \\
\cline { 3 - 7 } & & VI & VII & VIII & IX & X \\
\hline None & 0 & 25.0 & 0 & 0 & 0 & 0 \\
\hline Very light & 0.005 & 75.0 & 3.3 & 0 & 0 & 0 \\
\hline Light & 0.05 & 0.1 & 96.6 & 23.3 & 0 & 0 \\
\hline Moderate & 0.20 & 0 & 0.1 & 76.6 & 20.2 & 0 \\
\hline High & 0.45 & 0 & 0 & 0.1 & 79.8 & 20.9 \\
\hline Severe & 0.80 & 0 & 0 & 0 & 0 & 79.1 \\
\hline Collapse & 1.00 & 0 & 0 & 0 & 0 & 0 \\
\hline Mean damage factor (MDF) & 0.38 & 4.86 & 16.53 & 39.95 & 72.69 \\
\hline
\end{tabular}




\section{Conclusions}

For the two major Peruvian seismic zones, we have identified five types of school buildings as the most representative ones. One type corresponds to adobe buildings, three types are reinforced concrete-masonry (RC-M) buildings built before 1997 and the last ones are bigger RC-M buildings built after 1997.

If we consider that irreparable damage is when the mean damage factor (MDF) is higher than $60 \%$, results show that adobe buildings would be irreparable from VII MM of intensity, while RC-M buildings built before 1997 would be irreparable from VIII+ MM. New RC-M buildings would be irreparable from X MM.

For frequent earthquakes ( 50 years of return period), results show that the MDF in adobe buildings would be 45\%; in RC-M buildings built before 1997 around $20 \%$; and in new RC-M buildings just 5\%

For odd earthquakes (500 years of return period) results show that the MDF in adobe buildings would be $95 \%$; it would be about $65 \%$ for RC-M buildings built before 1997; and 38\% for new RC-M buildings.

The number of RC-M school buildings built following the 1997 Peruvian seismic design code represents only $2 \%$ of the total number of school buildings. Results show that only these buildings would be repairable after a severe seismic event.

\section{References}

[1] Ministerio de Educación del Perú, 2003. Cifras de la educación 1998-2003. Lima, Peru.

[2] Ministerio de vivienda, construcción y saneamiento. 2003. Norma técnica de diseño sismorresistente-NTE 030. Lima, Peru.

[3] ATC 13 (Applied Technology Council), 1985. Earthquake Damage Evaluation Data for California. Redwood City, California, USA.

[4] Linstone A, Turof M. 1975. The Delphi Method: Technique and Applications. Massachusetts, USA.

[5] Federal Emergency Management Agency. 1988. FEMA 154: Rapid Visual Screening of Buildings for Potential Seismic Hazards: A Handbook. Washington, USA. 